Figure A

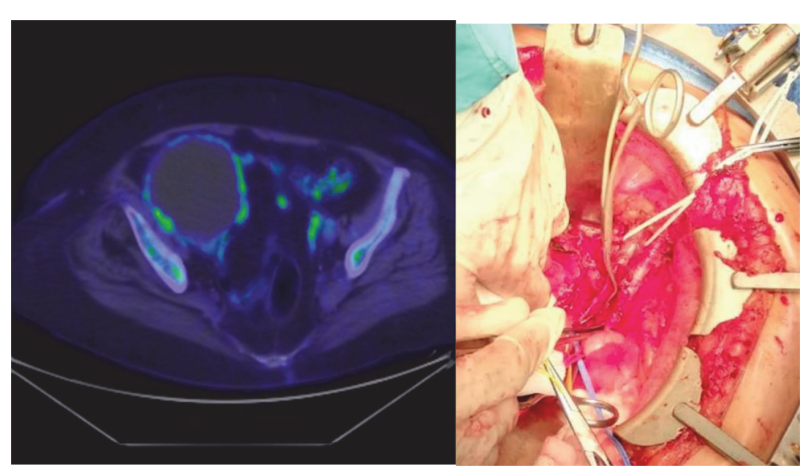

Abstract 600 Figure 1

The patient made an uneventful recovery with histology confirming metastatic disease.

Conclusion We present an overview of adamantinoma and highlight a previously undocumented gynaecological oncology surgical approach to this novel location of metastatic disease mimicking possible ovarian malignancy. We further explore disease histogenesis and also comment on an incidental finding or primary breast cancer. Particularly in uncommon locations, its heterogeneous nature presents radiological and histological challenges regarding diagnosis and treatment. Such cases warrant a full complement of MDT specialist knowledge and expertise; with advanced surgical skills and experience regarding retroperitoneal and pelvic sidewall anatomy. We also highlight a paucity of recommendations for surveillance and follow up and propose an individualised approach. We report on this unusual case to assist clinicians in the building of a consensus opinion for optimal adamantinoma case management under current circumstances where formal guidelines do not exist.

Disclosures None
Ovarian Cancer

\section{NIRAPARIB IN PATIENTS WITH NEWLY DIAGNOSED ADVANCED OVARIAN BRCAM CANCER: A POST HOC ANALYSIS OF THE PRIMA/ENGOT-OV26/GOG-3012 TRIAL}

${ }^{1}$ Jacob Korach, ${ }^{2}$ Whitney Graybill, ${ }^{3}$ Andrés Redondo, ${ }^{4}$ David M O'malley, ${ }^{5}$ Sileny Han ${ }^{6}$ Noelle Cloven, ${ }^{7}$ Anja Ør Knudsen, ${ }^{8}$ Stanislav Lechpammer, ${ }^{9}$ Antonio González-Martín, ${ }^{10}$ Bradley J Monk. 'Sheba Medical Center, Sackler School of Medicine, Tel Aviv University; Gynecologic Oncology Department; ${ }^{2}$ Gog; Medical University of South Carolina; Gynecologic Oncology; ${ }^{3}$ Hospital Universitario La Paz, Idipaz; ${ }^{4}$ Ohio State University, James Comprehensive Cancer Center; ${ }^{5}$ University Hospitals Leuven; Department of Obstetrics and Gynecology; ${ }^{6}$ Texas Oncology; ' Odense University Hospital; Department of Oncology; ${ }^{8}$ Glaxosmithkline; ${ }^{9}$ Grupo Español de Investigación En Cáncer de Ovario (Geico); Clínica Universidad de Navarra; Medical Oncology Department; ${ }^{10}$ Arizona Oncology (US Oncology Network); University of Arizona College of Medicine, Creighton University School of Medicine

\subsection{6/ijgc-2020-ESGO.220}

Introduction/Background The PRIMA/ENGOT-OV26/GOG3012 trial showed that niraparib significantly improves progression-free survival (PFS) in patients with newly diagnosed advanced ovarian cancer (aOC) that responded to front-line platinum-based chemotherapy (hazard ratio, 0.62; 95\% CI, 0.50-0.76). Based on these results, niraparib has been approved in the United States and the European Union for front-line maintenance treatment in patients with aOC. In this post hoc analysis, we report the efficacy of niraparib in patients with BRCA-mutated (BRCAm) aOC with an emphasis on efficacy and safety of fixed vs. individualized starting doses (FSD vs. ISD).

Methodology In this double-blind, placebo-controlled, randomised phase 3 trial, patients with newly diagnosed, high-grade aOC who responded to platinum-based chemotherapy were

Abstract 571 Table 1 PFS subgroup analysis analysis in patient with BRACAm

\begin{tabular}{|c|c|c|c|}
\hline & $\begin{array}{c}\text { Niraparib } \\
n=152\end{array}$ & $\begin{array}{c}\text { Placebo } \\
n=71\end{array}$ & Hazard ratio $(95 \% \mathrm{Cl})$ \\
\hline \multicolumn{4}{|c|}{ Starting dose cohort } \\
\hline FSD & 99 & 45 & $0.44(0.26-0.73)$ \\
\hline ISD & 53 & 26 & $0.29(0.13-0.67)$ \\
\hline \multicolumn{4}{|l|}{ Age category } \\
\hline$<65$ years & 109 & 54 & $0.45(0.27-0.74)$ \\
\hline$\geq 65$ years & 43 & 17 & $0.20(0.08-0.48)$ \\
\hline \multicolumn{4}{|c|}{ Neoadjuvant chemotherapy } \\
\hline Yes & 102 & 48 & $0.43(0.26-0.73)$ \\
\hline No & 50 & 23 & $0.35(0.17-0.72)$ \\
\hline
\end{tabular}

Abstract 571 Table 2 Summary of grade $\geq 3$ adverse events in patients with BRCAm aOC

\begin{tabular}{|c|c|c|c|c|}
\hline \multirow[b]{2}{*}{ Adverse event, no (\%) } & \multicolumn{2}{|c|}{ Niraparib } & \multicolumn{2}{|c|}{ Placebo } \\
\hline & $\begin{array}{l}\text { FSD } \\
n=99\end{array}$ & $\begin{array}{c}\text { ISD } \\
n=53\end{array}$ & $\begin{array}{l}\text { FSD } \\
n=45\end{array}$ & $\begin{array}{c}\text { ISD } \\
n=25\end{array}$ \\
\hline Thrombocytopenia events* & $49(49.5)$ & $10(18.9)$ & 0 & 0 \\
\hline Anaemia & $32(32.3)$ & $16(30.2)$ & $1(2.2)$ & 0 \\
\hline Neutropenia events $^{\dagger}$ & $18(18.2)$ & $7(13.2)$ & $1(2.2)$ & 0 \\
\hline Hypertension events ${ }^{\ddagger}$ & $9(9.1)$ & $1(1.9)$ & 0 & $2(8.0)$ \\
\hline \multicolumn{5}{|c|}{$\begin{array}{l}\text { aOC, advanced ovarian cancer; BRCAm, BRCA mutation; FSD, fixed starting dose; ISD, individualis } \\
\text { starting dose. } \\
{ }^{\star} \text { Thrombocytopenia events include thrombocytopenia and platelet count decreased. } \\
{ }^{\dagger} \text { Neutropenia events include neutrophil count decreased, neutropenia, and febrile neutropenia. } \\
\text { †Hypertension events include hypertension and blood pressure increased. }\end{array}$} \\
\hline
\end{tabular}


randomised 2:1 to receive FSD of niraparib $300 \mathrm{mg}$ orally once daily (QD) or placebo. The trial was amended to incorporate an ISD of $200 \mathrm{mg}$ orally QD for patients with a body weight $<77 \mathrm{~kg}$ or platelet count $<150,000 / \mu \mathrm{L}$, and $300 \mathrm{mg}$ QD in patients with a body weight $\geq 77 \mathrm{~kg}$ and platelet count $\geq 150,000 / \mu \mathrm{L}$. Patients were stratified by best response to firstline chemotherapy (complete/partial response), receipt of neoadjuvant chemotherapy (yes/no), and homologous recombination status (deficient/proficient and not determined). BRCA status was determined in tumour samples at screening via the myChoice test $\left(\operatorname{Myriad}^{\circledR}\right)$. The post hoc BRCAm subgroup PFS analysis was performed using a stratified Cox proportional hazards model and Kaplan-Meier methodology. Safety and patient-reported outcome analyses were also performed.

Results The intention-to-treat population comprised 733 randomised patients, of which 223 (30\%) had BRCAm tumours. Of those, $144(65 \%)$ received FSD and 79 (35\%) received ISD. Niraparib provided a comparable PFS benefit over placebo in patients receiving both FSD (hazard ratio, 0.44; 95\% CI $0.26-0.73$ ) and ISD (hazard ratio 0.29 ; 95\% CI $0.13-$ 0.67). A PFS subgroup analysis by patient characteristics is shown in table 1 . A summary of grade $\geq 3$ selected adverse events is shown in table 2 .

Conclusion Niraparib significantly improved PFS when utilised as maintenance treatment after front-line therapy in patients with BRCAm aOC. Patients receiving FSD or ISD derived similar PFS benefit, while the ISD group showed an improved safety profile.

Disclosures Dr. Graybill reports personal fees from GlaxoSmithKline.

Dr. Redondo reports institutional research funding from PharmaMar, Roche, and Eisai; and advisory roles at PharmaMar, AstraZeneca, Tesaro, Roche, and Eisai.

Dr. O’Malley reports personal fees from Immunogen, Eisai, Agenus, GlaxoSmithKline: Consultant/Advisory Board for Clovis, Ambry, Abbvie, Janssen/J\&J, Regeneron, Novacure, Myraid Genetics, Tarveda, Amgen, VentiRx, Array Biopharma, EMD Serono, Ergomed; Steering committee for Genentech/ Roche and Merck; Institutional funding from Ajinomoto Inc, Ludwig Cancer Research, Stemcentrx, Inc, CERULEAN PHARMA, GOG Foundation, BMS, Serono Inc, TRACON Pharmaceuticals, Yale University, New Mexico Cancer Care Alliance, INC Research, Inc., Inventiv Health Clinical, Iovance Biotherapeutics, Inc, and PRA International.

Dr. Gupta is an employee of GlaxoSmithKline.

Dr. González-Martín reports personal fees and non-financial support from AstraZeneca; grant and personal fees from GlaxoSmithKline, Clovis Oncology, Roche Holding AG, Merck \& Co., Inc., Genmab, INMUNOGEN, Pharma Mar, S.A., and Oncoinvent AS.

Dr. Monk reports consulting and advisory role at Merck, GlaxoSmithKline, Roche/Genentech, AstraZeneca, Advaxiz, Cerulean Pharma, Amgen, Immunogen, NuCana BioMed, Clovis Oncology, Pfizer, Mateon Therapeutics, Precision Oncology, Perthera, Abbvie, Myriad Pharmaceuticals, Incyte, VBL Therapeutics, Takeda, Samumed, Oncomed, OncoSec, ChemoID, Geistlich Pharma, Eisai and Chemocare; Speakers' bureau at Roche/Genentech, AstraZeneca, Janssen, Clovis Oncology and GlaxoSmithKline; Honoraria from Merck, GlaxoSmithKline, Roche/Genentech, AstraZeneca, Advaxis, Immunogen, NuCana BioMed, Clovis Oncology, Pfizer, Mateon Therapeutics, Precision Oncology, Pethera, Abbvie, Myriad Pharmaceuticals, Incyte, Janssen, Amgen, Genmab, Samumed, Takeda, VBL Therapeutics, Puma Biotechnology, Immunomedics, Conjupro
Biotherapeutics, Agenus, OncoQuest, ChemoID, Geistlich Pharma, Eisai and Chemocare; and Research funding from Novartis, Amgen, Genentech, Lilly, Janssen, Array BioPharma, GlaxoSmithKline, Morphotek, Pfizer, Advaxis, AstraZeneca, Immunogen, Regeneron, and Nucana.

Drs. Korach, Han, Cloven and Knudsen have nothing to disclose.

Funding GlaxoSmithKline (Waltham, MA)

\section{EPIDEMIOLOGY OF OVARIAN CANCER IN KAZAKHSTAN (2013-2018)}

Dilyara Kaidarova, Yerlan Kukubassov, Raikhan Bolatbekova, Alima Satanova. Kazakh Institute of Oncology and Radiology; Oncogynecology

\subsection{6/ijgc-2020-ESG0.221}

Introduction/Background Worldwide, ovarian cancer (OC) is the seventh most common cancer in women, with a five-year survival rate below $45 \%$. Every year around the world, OC is diagnosed in 240,000 women. Studies on the epidemiology of OC were carried out in different regions of the world, taking into account various factors. At the same time, the issues of the relationship between morbidity and mortality from OC with genetic, hormonal factors, as well as nutritional factors, morphometric factors, somatic pathology, socio-demographic and other factors were taken into account. The problem of OC epidemiology is extremely relevant for the Republic of Kazakhstan due to the significant prevalence of this disease among the female population, the still high level of neglected cases, as well as high mortality.

Methodology To analyze the epidemiological data of OC in the world, materials from the Globocan 2018 database of the International Agency for Research on Cancer (IARC) were used. To analyze the main statistical data for the regions of Kazakhstan, statistical data from the Cancer Register of the Republic of Kazakhstan for 2013-2018 were used.

Results In the Republic of Kazakhstan alone, there are more than 1000 new cases of OC and more than 400 deaths from this disease per year [5], while in the United States there are more than 22,000 new cases of OC and 14,000 deaths per year [6, 7]. In Kazakhstan, malignant neoplasms of the ovaries occupies the 3rd rank position among gynecological cancers. When analyzing rough intensive indicators of the incidence of ovarian cancer, there is an increase in the detection rate of this disease for the period from 2013 to 2018 [8-10]. The analysis of age-related incidence rates showed that malignant neoplasms of the ovaries are found in all age groups, with a noticeable increase by 65-69 years. The main contingent of the sick are women of working age. Also, when analyzing this five-year period (2013-2018), there is a decrease in the incidence in childhood and adolescence, so in 2014, 5 cases of ovarian cancer were recorded in the age group 5-19 years, and in 2019 - 1 case of this disease. Over the past decade, there has been an increase in morbidity at the age of 55-65 years [5].

Conclusion Morbidity and mortality from OC remain an urgent epidemiological problem in Kazakhstan and require further scientific research to identify risk factors. There are regions in the Republic of Kazakhstan that exceed the national average. In these regions, it is necessary to more widely apply modern methods of early diagnosis and treatment of ovarian cancer. If detected at earlier stages, it is possible to obtain 